\title{
Distinctive response of maize (Zea mays L.) genotypes in vitro with the acceleration of phytohormones
}

\author{
Sridevi Muppala - Pavan Kumar Gudlavalleti - Sreenu Pagidoju • Kodandarami Reddy Malireddy • \\ Sateesh Kumar Puligandla • Premalatha Dasari
}

Received: 2 January 2020 / Revised: 13 February 2020 / Accepted: 13 February 2020

(c) Korean Society for Plant Biotechnology

\begin{abstract}
In maize, immature embryos (IEs) are highly regenerative explants most suitable for producing high frequencies of plantlet regeneration in vitro. Apart from media, explants, and hormones, genotypic variation also influences in vitro characters to a great extent. In the present study, IEs were used to study the distinctive effect of variation of size/stage and hormones in different genotypes on five in vitro characters viz., frequency of callus induction, growth rate of total callus, frequency of E. callus induction, and volume and number of regenerated plantlets. LS medium with different concentrations of $2,4-\mathrm{D}(0.5,1.5,2.5$, 4.0 and $5.0 \mathrm{mg} / \mathrm{L}$ ) were used to study the former four in vitro characters, and medium with 6-benzylaminopurine and kinetin $(0.5 \mathrm{mg} / \mathrm{L}$, each $)$ was used for plantlet regeneration. IEs of 1.0, 1.5, 2.0, 2.5 and $3.0 \mathrm{~mm}$ in size were isolated from four inbred lines viz., NM74C, NM81A, NM5883 and
\end{abstract}

\section{Sridevi M.}

Deprtment of Biotechnology, Nuziveedu Seeds Limited,

Hyderabad, Telangana, India

Department of Biotechnology, Jawaharlal Nehru Technological

University, Hyderabad, Telangana, India

Pavan Kumar G. ( $\bowtie)$

Deprtment of Biotechnology, Nuziveedu Seeds Limited,

Hyderabad, Telangana, India

e-mail: pavankumar.g@nuziveeduseeds.com

Sreenu P.

Department of Clinical Epidemiology, ICMR-Natioanal Institute of Nutrition, Tarnaka, Jamai-Osmania PO, Hyderabad, India

Kodandarami Reddy M.

Department of Plant Molecular Biology, International Centre for

Genetic Engineering and Biotechnology, New Delhi, India

Sateesh Kumar P.

Deprtment of Biotechnology, Nuziveedu Seeds Limited,

Hyderabad, Telangana, India

Premalatha D.

Department of Biotechnology, Jawaharlal Nehru Technological

University, Hyderabad, Telangana, India
NM5884. Two-way ANOVA revealed that explant size and genotypes, as well as hormonal concentrations showed significant effects on in vitro characters. Two millimeter IEs were found to be suitable for in vitro cultures. LS medium with $1.5 \mathrm{mg} / \mathrm{L} 2,4-\mathrm{D}$ and LS with BAP and $\mathrm{Kn}(0.5 \mathrm{mg} / \mathrm{L}$, each) were found to be the best hormonal concentrations for callus induction, maintenance, and regeneration, respectively. Among the four genotypes, NM81A and NM5883 yielded more non-embryogenic and Type I E. calli. In contrast, NM74C and NM5884 yielded more highly regenerative Type II calli. Inbred line NM5884 was found to be the best among these four genotypes.

Keywords Embryogenic callus, Genotype, Growth rate, Immature embryo, In vitro regeneration, Zea mays L.

\section{Introduction}

Zea mays L, the queen of cereals, commonly called as maize, is the most important and major cereal crop occupied the third position next to rice and wheat because of its huge consumption in tropical and sub-tropical zones throughout the world. Its $\mathrm{C} 4$ photosynthetic mechanism makes this plant stood ahead among cereal crops in producing high grain yields and biomass through performing higher rates of photosynthetic activity. Not only food products, but it also has great value for producing industrial products (bioethanol), animal feed, and fodder. As it has diversified uses with higher productivity and adaptability, its demand was increased throughout the world, particularly in Asia. Hence, still several research programs are being done in all disciplines to improve its genome quality through adding, modifying or altering the traits of its genome not only through conventional breeding, but also using advanced biotechnological and molecular tools viz., tissue culture, 
genetic transformation and molecular assisted selection (MAS). Among the methods adopted in crop improvement, integration and expression of the defined genes into the plants through genetic transformation is the most widely used technique, for which reliable and highly reproducible in vitro protocol is pre-requisite. Callus induction and regeneration of maize were first reported by Green and Phillips (1975) using immature embryos. Since then, different studies have been carried out on regeneration of maize through organogenesis and somatic embryogenesis by using different explants namely, mature embryos (Al-Abed et al. 2006; Ali et al. 2014; Tiwari et al. 2015; Mushke et al. 2016), coleoptile nodes (Sreenu et al. 2016b; Pavan Kumar et al. 2018), nodal regions (Vladimir et al. 2006), leaf tissues (Conger et al. 1987; Ray and Ghosh 1990; Ahmadabadi et al. 2007), anthers (Barloy and Beckert 1993; Ismaili and Mohammadi 2016), tassel and ear meristems (Pareddy and Petolino 1990), protoplast (Morocz et al. 1990), and shoot meristems (Zhong et al. 1992; O'Connor et al. 2002; Sairam et al. 2003). Further studies revealed that immature embryos (IEs) are the most widely used explants than any other explants, because of their high efficiencies in giving embryogenic calli and regeneration. Though the model genotype of maize, A188, and its hybrid, Hi-II are known to yield high frequency of embryogenic callus and plantlet regeneration, they have poor agronomical values, which raise the necessity to search a wide range of genotypes for identifying the high regenerative lines. The genotype of the plant plays very crucial role on in vitro plant response. Hence it is necessary to screen the local lines that would be widely used in the breeding programmes. Inbred lines, which involved in the development of commercially successful hybrids, have to be screened for knowing their in vitro competency to regenerate plantlets. Along with the genotype, explants and its size and hormonal concentrations and combinations influence the in vitro response. Hence, the present study has been undertaken to study the distinctive in vitro response of maize genotypes through studying the effect of different hormonal concentrations and combinations and explant sizes on five in vitro characters viz., frequency of callus induction, callus growth rate, frequency of embryogenic callus induction, its volume and number of plantlets regenerated by using immature embryos.

\section{Materials and Methods}

Plant material

Seeds of four inbred maize lines (NM74C, NM81A, NM5883, and NM5884) of Nuziveedu Seeds Limited were sown in the field. To ensure the supply of immature embryos (IEs) continuously, staggered planting was adapted, and seeds were sown in four lines in $3 \sim 4$ days intervals. Plants were allowed to grow until flowering, and cobs were masked with butter paper bags before the emergence of silk, which were hand pollinated.

\section{Isolation of explants}

Ears were collected on different days after pollination $(8 \sim 20$ days); after removing sheaths, naked cobs were surface sterilized for $15 \mathrm{~min}$ using a 10\% sodium hypochlorite (4\% w/v) solution along with few drops of surfactant, Tween 20. Then the cobs were thoroughly washed three times with sterile distilled water (five min each). After kernel crowns were removed using a sterile scalpel, different sizes of embryos were carefully isolated and inoculated on callus induction medium by keeping the scutellar side facing up and flat surface down. These culture plates were incubated in the dark at $26 \pm 1^{\circ} \mathrm{C}$.

\section{Callus induction Medium}

Linsmaier and Skoog's (LS) medium (Linsmaier and Skoog, 1965) supplemented with different concentrations of 2 , 4-dichloro phenoxyacetic acid (2,4-D) viz., 0.5, 1.5, 2.5, 4.0 and $5.0 \mathrm{mg} / \mathrm{L}$ along with $0.7 \mathrm{~g} / \mathrm{L}$ L-proline, $0.5 \mathrm{~g} / \mathrm{L}$ MES, $20 \mathrm{~g} / \mathrm{L}$ sucrose and $3 \mathrm{~g} / \mathrm{L}$ gelrite were used for callus induction. The $\mathrm{pH}$ of the medium was adjusted to 5.8 before adding gelrite and then autoclaved at $121^{\circ} \mathrm{C}$ temperature with $15 \mathrm{lbs}$ pressure for 15 minutes. Filter sterilized silver nitrate $\left(\mathrm{AgNO}_{3}\right)$ solution at a concentration of $1.7 \mathrm{mg} / \mathrm{L}$ was added to the medium after autoclaving.

Maintenance of cultures and parameters measured

After twelve days of inoculation, embryo axes were removed, and primary calli were sub-cultured onto the same media, which is repeated periodically until they were transferred onto the regeneration medium. These cultures were maintained in the dark at the same temperature $\left(26 \pm 1^{\circ} \mathrm{C}\right)$. In vitro parameters, viz., frequency of callus induction, the growth rate of total callus, frequency of embryogenic callus induction, and its volume were studied in all genotypes. Explants and/or calli cultured on basal LS medium with no phytohormones were served as controls throughout this study. Callus induction was represented as frequency and calculated as the number of explants induced the callus; growth rate of total callus was represented as percentage of increase in 
callus growth during the I, II and III sub-cultures, in terms of increase in callus volume; Immature embryo explants, after removing the developed radicals, were allowed to grow in same conditions. After 12 days, proliferated callus was measured for the volume and it is considered as initial volume of the callus. Then calli were transferred onto the same medium. All the calli derived from different genotypes, different sizes of IEs and concentrations of 2,4-D were maintained separately and data were collected for measuring the growth rate of callus individually to evaluate the genotypic / hormonal / explant size effect on callus growth rate. The measurements i.e., volume of the calli were taken at an interval of two weeks. The volume at zero weeks, while transferring onto fresh medium, was designated as initial volume and then transferred onto the respective media; after two weeks, at the end of I sub-culture, again the volumes of calli were measured and calculated the growth rate and represented as per cent of increase in volume. After taking the data, again calli were sub-cultured onto the fresh medium having the same constituents. These were repeated for two more times at the end of four and six weeks i.e., at the end of II and III sub-cultures. Embryogenic callus induction has also been represented as frequency and calculated as the number of calli induced embryogenic callus; embryogenic callus volume was represented as its volume in cubic millimeters before going to transfer onto the regeneration medium.

\section{Regeneration, Rooting, and Acclimatization of plants}

Embryogenic calli were transferred onto regeneration medium i.e., LS medium supplemented with $0.5 \mathrm{~g} / \mathrm{L} \mathrm{MES}, 10 \mu \mathrm{M} \mathrm{CuSO}_{4}$, $20 \mathrm{~g} / \mathrm{L}$ sucrose, $3 \mathrm{~g} / \mathrm{L}$ gelrite and growth regulators viz., 6-benzylaminopurine (BAP) and kinetin (Kn) each at a concentration of $0.5 \mathrm{mg} / \mathrm{L}$. Cultures were maintained at $26 \pm 1^{\circ} \mathrm{C}$ with $16 \mathrm{~h}$ light $8 \mathrm{~h}$ dark cycle. After two weeks, shoots were counted as number of plantlets grown from each embryogenic callus mass developed from a single explant. Regenerated shoots of $3 \sim 4 \mathrm{~cm}$ height were transferred onto rooting medium i.e., MS basal (Murashige and Skoog 1962) having 0.8\% agar. Profusely rooted plantlets were transferred to plastic cups filled with autoclaved cocopeat and covered with polythene bags, which were maintained at an ambient temperature of $28 \pm 1{ }^{\circ} \mathrm{C}$ for primary hardening. After acclimatization, plants were moved to poly house and kept for 2 days in the same conditions. Then, the polythene covers were removed and transferred onto the soil for further growth.
Statistical analysis

Statistical analyses were done to evaluate the effect of IEs size and hormonal concentrations among different genotypes on different in vitro parameters. Raw data were collected from three replications and subjected to two-way ANOVA (Snedecor and Cochran 1968).

\section{Results}

In vitro regeneration of maize by using immature embryo explants

Cobs of different ages i.e., days after pollination, were harvested and sterilized; then, IEs of six different sizes viz., 1, 1.5, 2, 2.5, 3 and $3.5 \mathrm{~mm}$ were isolated (Fig. 1A, B and C) and inoculated onto the media supplemented with different concentrations of 2,4-D $(0.5,1.5,2.5,4.0$ and 5.0 $\mathrm{mg} / \mathrm{L}$ ) for evaluating the effect of size or age of IEs and phytohormonal concentrations on five in vitro characters among four maize genotypes. The last one (number of plantlets regenerated) was studied by supplementing BAP and Kn each at a concentration of $0.5 \mathrm{mg} / \mathrm{L}$.

Primary callus induction

IEs isolated from any of these four genotypes inoculated onto the medium lacking 2,4-D (control) seldom initiated callus from any of their sizes, but resulted in profuse roots and shoots (Fig. 1D). IEs of sizes $<1$ and $>=3.5 \mathrm{~mm}$ did not respond in giving callus in any of the genotypes (Fig. $1 \mathrm{E}$ and $\mathrm{F}$ ), hence data has not been presented. Callus initiation was observed from the explants after $7 \sim 8$ day of inoculation. Among the explants, very small and large IEs measuring 1 and $3 \mathrm{~mm}$ were not suitable and showed no callus induction in NM81A and NM5883 in any of the 2,4-D concentrations, whereas very low induction percentages were observed in NM74C and NM5884 at medium 2,4-D concentrations (1.5 and $2.5 \mathrm{mg} / \mathrm{L}$ ) (Fig. 2). Only 1.5 and $2 \mathrm{~mm}$ size IEs showed callus induction in NM81A and NM5883 in all 2,4-D concentrations except at $5.0 \mathrm{mg} / \mathrm{L}$ in $1.5 \mathrm{~mm}$ size explants. On the other hand, three sizes of IEs viz., 1.5, 2 and $2.5 \mathrm{~mm}$ resulted in callus induction in NM74C as well as NM5884 with varying degree of variation in frequency at all 2,4-D concentrations (Fig. 2). When the genotypes were considered, NM74C and NM5884 resulted in callus induction from all sizes of explants with higher frequencies than other two genotypes viz., NM81A 


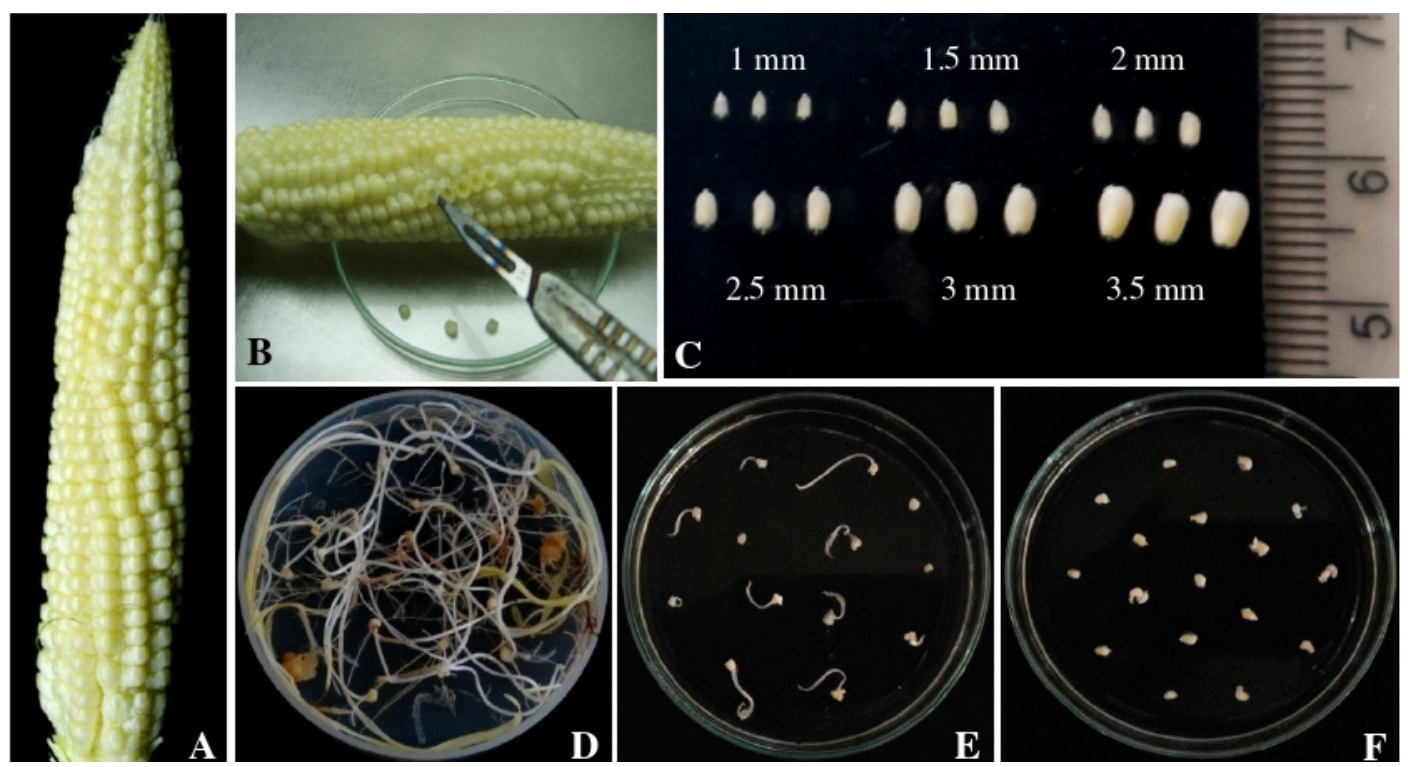

Fig. 1 Explant (immature embryos) source (A), dissection and isolation of different sizes of explants (B \& C), and their initial response on media supplemented with different concentrations of 2,4-D (D-F) in maize (Zea mays L.); immature embryos of $2 \mathrm{~mm}$ in size inoculated on the medium lacking hormones develop profuse roots and shoots without callus induction (D), immature embryos of $<1$ and $>3 \mathrm{~mm}$ in size inoculated on the medium supplemented with 2,4-D seldom initiate callus formation (E \& F)
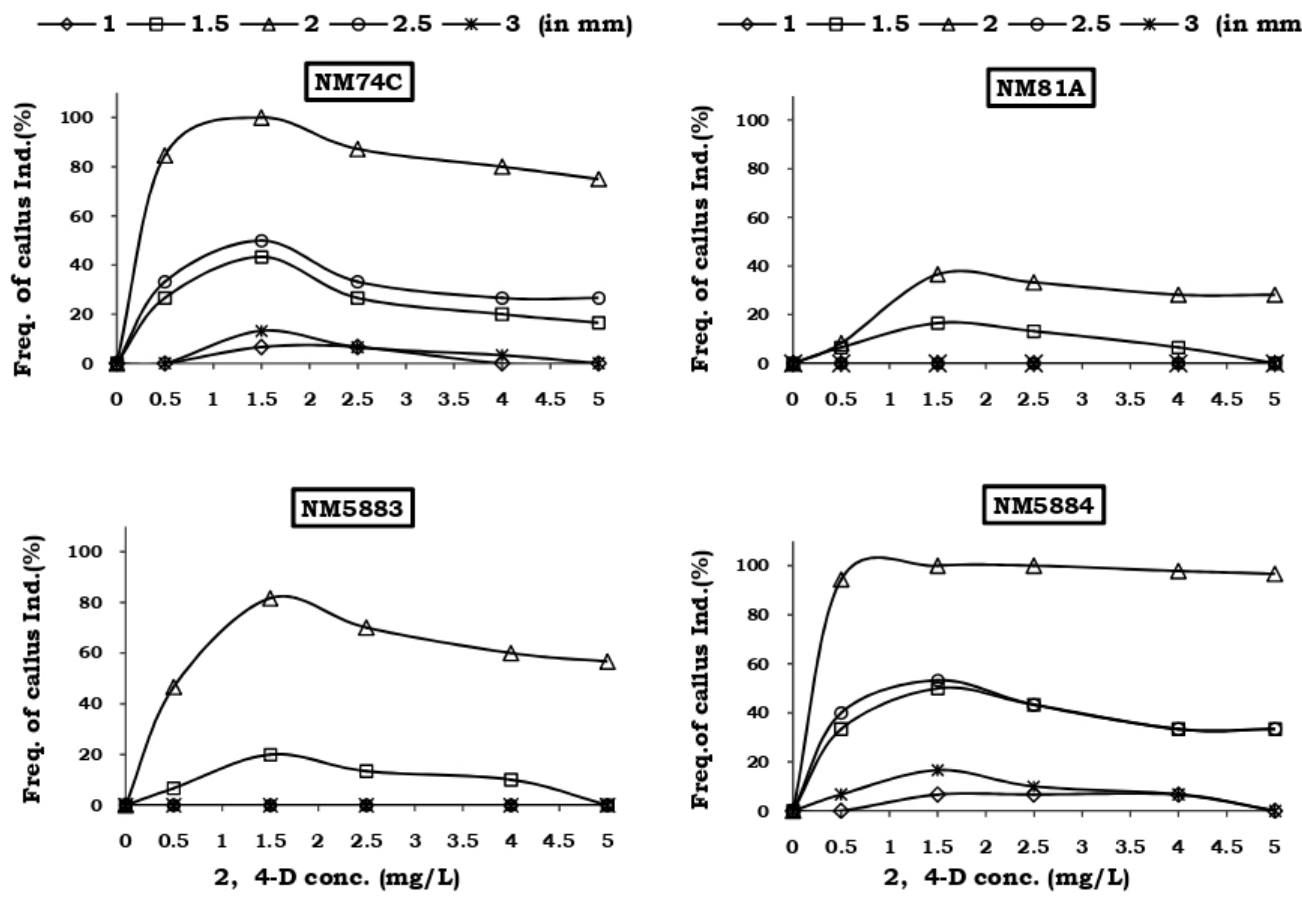

Fig. 2 Effect of 2,4-D concentrations and different sizes of immature embryos on frequency of callus induction in different genotypes (inbred lines) of maize

and NM5883 by having variation among 2,4-D concentrations (Fig. 2). Frequency of callus induction was widely ranged from 6.66 to $100 \%$ in different sizes of explants, 2,4-D concentrations and genotypes used. Frequency of callus induction was increased with increasing 2,4-D concentration up to $1.5 \mathrm{mg} / \mathrm{L}$, then decreased in further concentrations not only in any of the genotypes but also in sizes of the explants (Fig. 2), and also increased with increasing size of the explants up to $2 \mathrm{~mm}$ and then decreased in further explant sizes. Though the maximum frequency of callus induction (100\%) was observed in both the genotypes of NM74C and NM5884 in $2 \mathrm{~mm}$ size IEs at $1.5 \mathrm{mg} / \mathrm{L}$ 2,4-D, frequencies at other concentrations of 2,4-D and explant sizes were on the higher side in NM5884 than NM74C. 
Table 1 Analysis of variance of the effect of phytohormonal (2,4-D) concentrations, size of the immature embryos, and inbred lines on frequency of callus induction

\begin{tabular}{|c|c|c|c|}
\hline & Source of variation & MS & $F$ - value \\
\hline \multicolumn{4}{|l|}{ In Different Inbred Lines } \\
\hline NM74C & Between 2,4-D concentrations & 1003.65 & $5.08^{*}$ \\
\hline & Between IE sizes & 4664.93 & $23.61 *$ \\
\hline NM81A & Between 2,4-D concentrations & 78.95 & 1.69 \\
\hline & Between IE sizes & 572.41 & $12.32 *$ \\
\hline NM5883 & Between 2,4-D concentrations & 241.26 & 1.54 \\
\hline & Between IE sizes & 3127.94 & $20.05^{*}$ \\
\hline NM5884 & Between 2,4-D concentrations & 1296.72 & $5.28^{*}$ \\
\hline & Between IE sizes & 5871.68 & $23.93 *$ \\
\hline \multicolumn{4}{|c|}{ In Different Concentrations of 2,4-D } \\
\hline $0.50 \mathrm{mg} / \mathrm{L}$ & Between Inbred Lines & 1126.31 & $4.19^{*}$ \\
\hline & Between IE sizes & 2222.77 & $8.29 *$ \\
\hline $1.50 \mathrm{mg} / \mathrm{L}$ & Between Inbred Lines & 1437.47 & $8.03 *$ \\
\hline & Between IE sizes & 3699.11 & $20.66^{*}$ \\
\hline $2.50 \mathrm{mg} / \mathrm{L}$ & Between Inbred Lines & 1017.12 & $7.14^{*}$ \\
\hline & Between IE sizes & 3206.09 & $22.53^{*}$ \\
\hline $4.00 \mathrm{mg} / \mathrm{L}$ & Between Inbred Lines & 802.01 & $5.76^{*}$ \\
\hline & Between IE sizes & 2836.35 & $20.39 *$ \\
\hline $5.00 \mathrm{mg} / \mathrm{L}$ & Between Inbred Lines & 738.77 & $4.47^{*}$ \\
\hline & Between IE sizes & 2817.72 & $17.05^{*}$ \\
\hline \multicolumn{4}{|c|}{$\underline{\text { In Different Sizes of Immature Embryos }}$} \\
\hline $1.00 \mathrm{~mm}$ & Between Inbred Lines & 16.63 & $3.46^{*}$ \\
\hline & Between 2,4-D concentrations & 10.72 & 2.23 \\
\hline $1.50 \mathrm{~mm}$ & Between Inbred Lines & 857.42 & $20.48^{*}$ \\
\hline & Between 2,4-D concentrations & 481.01 & $11.49 *$ \\
\hline $2.00 \mathrm{~mm}$ & Between Inbred Lines & 4019.13 & $20.51 *$ \\
\hline & Between 2,4-D concentrations & 3317.81 & $16.94 *$ \\
\hline $2.50 \mathrm{~mm}$ & Between Inbred Lines & 1966.33 & $19.59^{*}$ \\
\hline & Between 2,4-D concentrations & 295.16 & $2.94 *$ \\
\hline $3.00 \mathrm{~mm}$ & Between Inbred Lines & 63.36 & $5.31 *$ \\
\hline & Between 2,4-D concentrations & 32.66 & 2.74 \\
\hline
\end{tabular}

*significant at $p=0.05$

NM5884 resulted in higher frequencies of callus induction than other genotypes in all concentrations and explant sizes. Even in the NM5884 genotype, distinctive variation was observed in the callus induction among different sizes of explants. This wide range of variation observed in the frequencies of callus induction among the genotypes, 2,4-D concentrations and sizes of explants was subjected to two-way analysis of variance (ANOVA), which revealed that all genotypes showed significant variation among the 2,4-D concentrations as well as sizes of explants except in NM81A and NM5883 between 2,4-D concentrations (Table 1), which indicated that, not only the hormonal concentrations but also size of the explants showed significant effect on frequency of callus induction (Table 1). It also revealed that, at all 2,4-D concentrations and sizes of IEs, inbred lines showed significant effect on frequency of callus induction. Size of the explants showed significant effect on frequencies of callus induction at all 2,4-D concentrations, likewise, 2,4-D concentrations have also showed significant effect on callus induction except in the explants measuring 1 and $3 \mathrm{~mm}$ (Table 1).

Total callus growth rate

Explants of 1 and $3 \mathrm{~mm}$ sizes did not show callus growth in any of four genotypes and three sub-cultures at 0.5 and $5.0 \mathrm{mg} / \mathrm{L} \mathrm{2,4-D} \mathrm{concentrations.} \mathrm{When} \mathrm{the} \mathrm{growth} \mathrm{rate} \mathrm{among}$ genotypes was taken into consideration, the genotypes viz., NM81A and NM5883 showed significantly lower rate in their growth when compared with other two genotypes. 1 and $3 \mathrm{~mm}$ explants of these two genotypes did not show any growth in any of 2,4-D concentrations and also in 


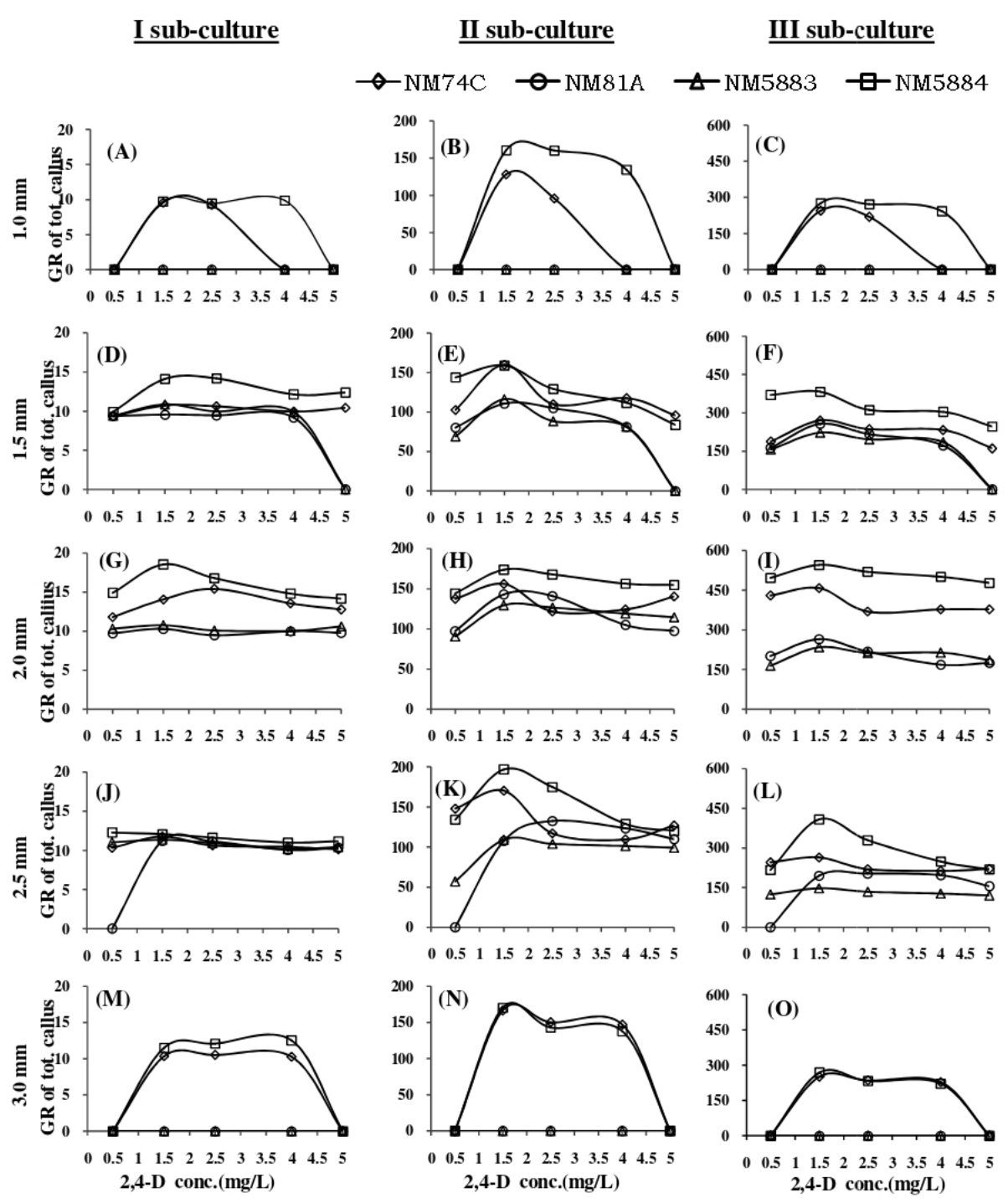

Fig. 3 Effect of a range of concentrations of 2,4-D on growth rate (percent increase in volume) of total callus developed from different sizes of immature embryos isolated from different inbred lines of maize at three growth stages

any of sub-cultures (Fig. 3). Almost both of these genotypes showed similar growth rates and pattern at first sub-culture, whereas some discrepancies were observed among these two in II and III sub-cultures respectively in $2 \mathrm{~mm}$ explants size on 1.5 and $2.5 \mathrm{mg} / \mathrm{L}$ 2,4-D concentrations. On the other hand, two other genotypes viz., NM74C and NM5884 resulted in better growth rates at each sub-culture and 2,4-D concentrations with all sizes of explants than NM81A and NM5883. Though the difference in growth rate between NM74C and NM5884was not significant enough in first sub-culture, they showed significant differences in II and III sub-cultures particularly in $2 \mathrm{~mm}$ size IEs, where the genotype NM5884 resulted in maximum rate of its growth in all concentrations of 2,4-D used. Among the genotypes used in present study, maximum growth rates of calli were observed with NM5884 followed by NM74C, NM81A and
NM5883 genotypes in this given order at all 2,4-D concentrations and explants sizes respectively during II and III sub-cultures (Fig. 3).

Data on callus growth rate obtained from different concentrations of 2,4-D, sizes of explants of four genotypes at three sub-cultures were subjected to two-way ANOVA, it revealed that 2,4-D concentrations and explants size influence significantly in all genotypes except in NM81A in first sub-culture (Table 2); significant variation was observed between explant sizes in all 2,4-D concentrations except at $2.5 \mathrm{mg} / \mathrm{L}$ in II sub-culture, whereas, between inbred lines, at medium 2,4-D concentrations $(1.5,2.5$ and $4.0 \mathrm{mg} / \mathrm{L})$ significant variation was observed in all sub-cultures. In contrary, at $0.5 \mathrm{mg} / \mathrm{L}$ (low) 2,4-D concentration, significant variation was observed in II and III sub-cultures; and in $5.0 \mathrm{mg} / \mathrm{L}$ (high) concentration significant variation was ob- 
Table 2 Analysis of variance of the effect of phytohormonal concentrations, size of the immature embryos, and inbred lines on callus growth rate

\begin{tabular}{|c|c|c|c|c|c|c|c|}
\hline \multirow{2}{*}{\multicolumn{2}{|c|}{ Source of variation }} & \multicolumn{2}{|c|}{ I Sub-Culture } & \multicolumn{2}{|c|}{ II Sub-Culture } & \multicolumn{2}{|c|}{ III Sub-Culture } \\
\hline & & MS & $F$ - value & MS & $F-$ value & MS & $F$ - value \\
\hline \multicolumn{8}{|c|}{ In Different Inbred Lines } \\
\hline \multirow[t]{2}{*}{ NM74C } & Between 2,4-D concs. & 88.84 & $9.89 *$ & 13832.24 & $8.71 *$ & 53716.25 & $8.68^{*}$ \\
\hline & Between IE sizes & 62.26 & $6.93 *$ & 5974.96 & $3.76^{*}$ & 57835.61 & $9.35^{*}$ \\
\hline \multirow[t]{2}{*}{ NM81A } & Between 2,4-D concs. & 27.78 & 2.61 & 4046.31 & $3.24 *$ & 13456.88 & $3.26^{*}$ \\
\hline & Between IE sizes & 96.18 & $9.01 *$ & 12322.93 & $9.87 *$ & 38976.71 & $9.45^{*}$ \\
\hline \multirow[t]{2}{*}{ NM5883 } & Between 2,4-D concs. & 31.89 & $3.89 *$ & 3275.01 & $3.93 *$ & 9982.01 & $3.81^{*}$ \\
\hline & Between IE sizes & 122.88 & $14.99 *$ & 12036.81 & $14.45^{*}$ & 35512.19 & $13.54^{*}$ \\
\hline \multirow[t]{2}{*}{ NM5884 } & Between 2,4-D concs. & 127.16 & $12.58^{*}$ & 20363.33 & $13.87^{*}$ & 91983.57 & $12.67 *$ \\
\hline & Between IE sizes & 69.46 & $6.87^{*}$ & 4386.21 & $2.98 *$ & 90634.63 & $12.49^{*}$ \\
\hline \multicolumn{8}{|c|}{ In Different Concentrations of $2,4-\mathrm{D}(\mathrm{mg} / \mathrm{L})$} \\
\hline \multirow[t]{2}{*}{0.50} & Between Inbred Lines & 11.41 & 1.75 & 4617.82 & $3.98^{*}$ & 23399.36 & $3.55^{*}$ \\
\hline & Between IE sizes & 122.61 & $18.84^{*}$ & 11400.92 & $9.85^{*}$ & 79091.67 & $12.02 *$ \\
\hline \multirow[t]{2}{*}{1.50} & Between Inbred Lines & 59.98 & $8.13^{*}$ & 14476.09 & $11.21 *$ & 75488.93 & $29.74 *$ \\
\hline & Between IE sizes & 61.09 & $8.27 *$ & 5421.56 & $4.21 *$ & 44462.41 & $17.52 *$ \\
\hline \multirow[t]{2}{*}{2.50} & Between Inbred Lines & 61.04 & $8.30 *$ & 8744.93 & $5.61 *$ & 57183.19 & $19.14^{*}$ \\
\hline & Between IE sizes & 54.11 & $7.36^{*}$ & 4594.89 & 2.95 & 31623.35 & $10.58^{*}$ \\
\hline \multirow[t]{2}{*}{4.00} & Between Inbred Lines & 42.72 & $5.09 *$ & 6141.45 & $3.98^{*}$ & 44914.79 & $11.16^{*}$ \\
\hline & Between IE sizes & 63.61 & $7.58^{*}$ & 5557.51 & $3.61^{*}$ & 39219.28 & $9.75^{*}$ \\
\hline \multirow[t]{2}{*}{5.00} & Between Inbred Lines & 15.54 & 1.91 & 1501.14 & 3.01 & 20135.68 & $4.13^{*}$ \\
\hline & Between IE sizes & 125.77 & $15.42 *$ & 14773.01 & $29.64 *$ & 66441.57 & $13.63^{*}$ \\
\hline \multicolumn{8}{|c|}{ In Different Sizes of Immature Embryos (in mm) } \\
\hline \multirow[t]{2}{*}{1.00} & Between Inbred Lines & 34.79 & $3.49 *$ & 7914.86 & $3.99 *$ & 24908.58 & $3.74^{*}$ \\
\hline & Between 2,4-D concs. & 21.91 & 2.19 & 4515.84 & 2.27 & 15501.94 & 2.32 \\
\hline \multirow[t]{2}{*}{1.50} & Between Inbred Lines & 22.08 & $3.45^{*}$ & 3272.76 & $8.68^{*}$ & 25626.92 & $12.07 *$ \\
\hline & Between 2,4-D concs. & 77.87 & $12.17 *$ & 9829.21 & $26.08^{*}$ & 44996.32 & $21.18^{*}$ \\
\hline \multirow[t]{2}{*}{2.00} & Between Inbred Lines & 32.93 & $15.51^{*}$ & 1741.74 & $9.43 *$ & 95501.73 & $22.74 *$ \\
\hline & Between 2,4-D concs. & 104.23 & $49.09 *$ & 12164.51 & $65.91 *$ & 74795.53 & $17.81^{*}$ \\
\hline \multirow[t]{2}{*}{2.50} & Between Inbred Lines & 7.15 & 1.39 & 3429.41 & $3.71^{*}$ & 21507.19 & $7.08^{*}$ \\
\hline & Between 2,4-D concs. & 76.94 & $15.02 *$ & 11050.36 & $11.97 *$ & 31900.82 & $10.51^{*}$ \\
\hline \multirow[t]{2}{*}{3.00} & Between Inbred Lines & 63.34 & $4.99 *$ & 11601.35 & $4.94 *$ & 28606.65 & $4.95^{*}$ \\
\hline & Between 2,4-D concs. & 37.61 & $2.96^{*}$ & 7036.37 & $2.99 *$ & 17292.13 & $2.99 *$ \\
\hline
\end{tabular}

*significant at $p=0.05$

served only in III sub-culture (Table 2). On the other hand, in $1 \mathrm{~mm}$ size explants, no significant effect was observed between 2,4-D concentrations in any of three sub-cultures. In other sizes of the explants (1.5 to $3 \mathrm{~mm}$ ) variation was significant in all three sub-cultures. Significant variation was observed between genotypes in all sizes of explants and three sub-cultures, except in $2.5 \mathrm{~mm}$ at I sub-culture (Table 2). Callus growth rate showed significant variation at all growth stages between genotypes and in all explants sizes.

Embryogenic callus induction

Among the four genotypes used, NM74C and NM5884 were chosen to study other two in vitro characters viz., frequency of E. callus induction and volume of E. callus obtained at different sizes of explants maintained on different concentrations of 2,4-D. Induction of embryogenic callus was observed at the end of II sub-culture from the calli maintaining on different 2,4-D concentrations. E. callus induction was observed in all calli, except the calli derived from $1 \mathrm{~mm}$ explants maintained on $0.5,4.0$ and $5.0 \mathrm{mg} / \mathrm{L}$ 2,4-D concentrations and also in $3 \mathrm{~mm}$ explants maintained on 0.5 and $5.0 \mathrm{mg} / \mathrm{L} 2,4-\mathrm{D}$ concentrations. In NM74C, E. callus induction was comparatively less than in NM5884, in all 2,4-D concentrations and explant sizes. Frequency of E. callus induction was ranged from 23.52 to 90.37 per cent in NM74C, whereas it was ranged from 30.40 to 100 per cent in NM5884. Highest frequency (100 per cent) of E. callus induction was observed from the calli derived 
$\underline{\text { NM74C }}$
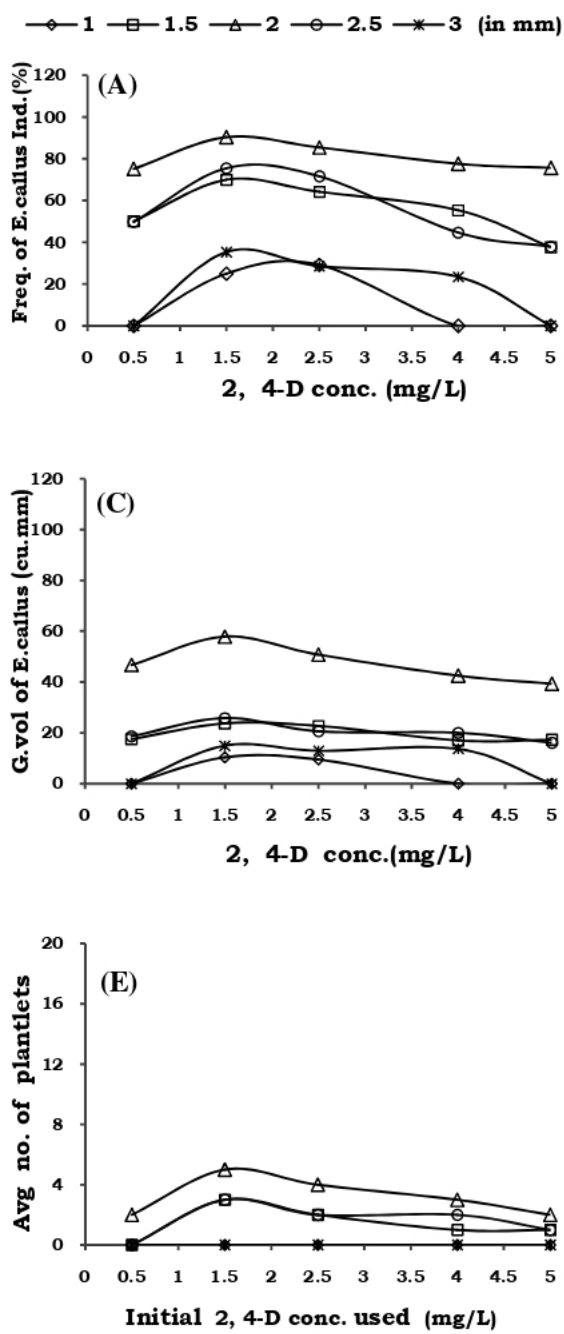

$\underline{\text { NM5884 }}$
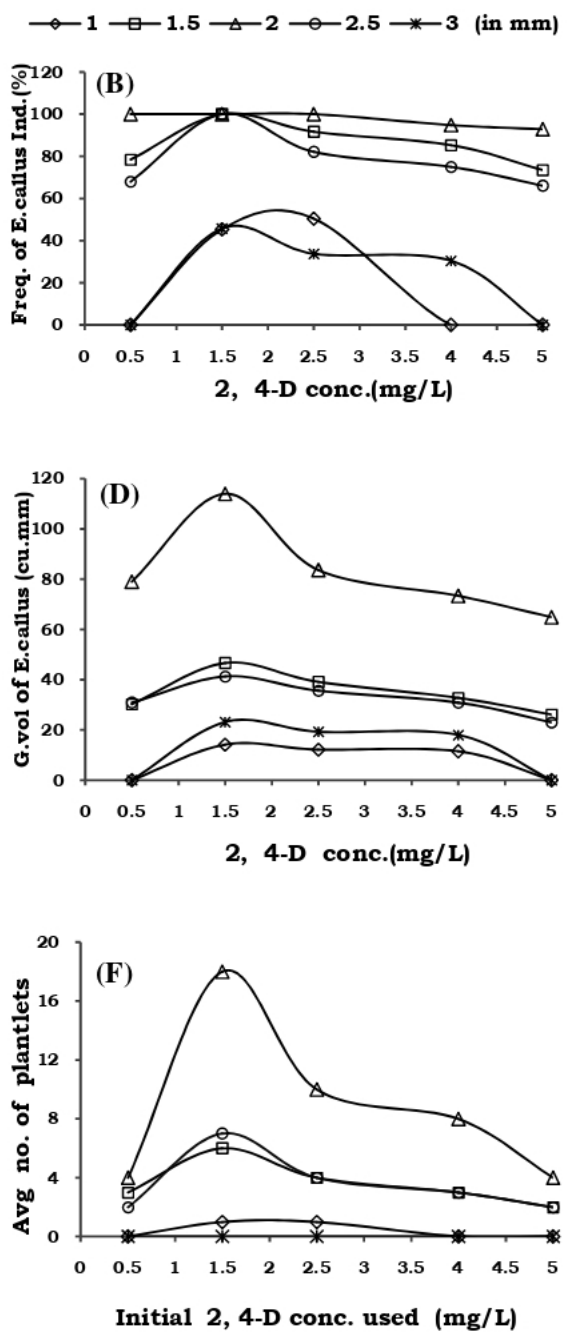

Fig. 4 Frequency of E. callus induction (A \& B), volume (C \& D), and average number of plantlets (E \& F) regenerated from different sizes of immature embryos from different inbred lines cultured on media supplemented with a range of concentrations of 2,4-D.

from $2 \mathrm{~mm}$ size explants of NM5884 on three of five 2,4-D concentrations used for total callus maintenance (viz., 0.5, 1.5 and $2.5 \mathrm{mg} / \mathrm{L}$ ) (Fig. 4A and B). In both the genotypes, frequency of E. callus induction was increased with increasing size of explants up to $2 \mathrm{~mm}$ and then decreased with further increase in size except in calli derived from $1.5 \mathrm{mg} / \mathrm{L}$ of 2,4-D in NM5884. The same trend has also been observed with 2,4-D concentrations, where increase in frequency of E. callus induction was observed up to $1.5 \mathrm{mg} / \mathrm{L}$ and then decreased in further concentrations except in $2 \mathrm{~mm}$ size explants of NM5884 (Fig. 4 A and B). When the data was subjected to two-way ANOVA, in both the genotypes, significant variation was observed not only between 2,4-D concentrations but also in explant sizes. Variation observed in frequency of E. callus induction was significant between explant sizes at all 2,4-D concentrations, whereas, significant variation was observed between genotypes only at 1.5, 2.5 and $4.0 \mathrm{mg} / \mathrm{L}$ 2,4-D concentrations, and no significant variation was observed at low and high $(0.5$ and $5.0 \mathrm{mg} / \mathrm{L}$ respectively) 2,4-D concentrations. On the other hand, variation was significant between the genotypes in all explant sizes except in $2 \mathrm{~mm}$, whereas significant variation between 2,4-D concentrations were observed only at 1.5, 2.5 and $4.0 \mathrm{mg} / \mathrm{L}$ concentrations, but not at low and high (1 and 3 $\mathrm{mm}$ respectively) sizes of explants (Table 3 ).

Embryogenic callus volume

E. calli induced in II sub-culture were allowed to grow for two weeks and at the end of III sub-culture, its volumes were measured and data was collected (Fig. 4C and D). At this stage E. callus was fully grown. Based on the texture 
Table 3 Analysis of variance of the effect of phytohormonal (2,4-D) concentrations, size of the immature embryos, and inbred lines on frequency of embryogenic callus induction

\begin{tabular}{|c|c|c|c|}
\hline & Source of variation & MS & $F$ - value \\
\hline \multicolumn{4}{|c|}{ In Different Inbred Lines } \\
\hline \multirow{2}{*}{$\mathrm{NM} 74 \mathrm{C}$} & Between 2,4-D concs. & 822.35 & $20.81 *$ \\
\hline & Between IE sizes & 4291.1 & $108.58^{*}$ \\
\hline \multirow[t]{2}{*}{ NM5884 } & Between 2,4-D concs. & 963.17 & $8.13^{*}$ \\
\hline & Between IE sizes & 6899.61 & $58.27 *$ \\
\hline \multicolumn{4}{|c|}{ In Different Concentrations of 2,4-D } \\
\hline \multirow[t]{2}{*}{$0.50 \mathrm{mg} / \mathrm{L}$} & Between Inbred Lines & 508.55 & 5.56 \\
\hline & Between IE sizes & 3193.33 & $34.96^{*}$ \\
\hline \multirow[t]{2}{*}{$1.50 \mathrm{mg} / \mathrm{L}$} & Between Inbred Lines & 896.04 & $22.89 *$ \\
\hline & Between IE sizes & 1622.95 & $41.46^{*}$ \\
\hline \multirow[t]{2}{*}{$2.50 \mathrm{mg} / \mathrm{L}$} & Between Inbred Lines & 617.91 & $15.98 *$ \\
\hline & Between IE sizes & 1422.83 & $36.81^{*}$ \\
\hline \multirow[t]{2}{*}{$4.00 \mathrm{mg} / \mathrm{L}$} & Between Inbred Lines & 711.04 & $7.75^{*}$ \\
\hline & Between IE sizes & 2423.57 & $26.42 *$ \\
\hline \multirow[t]{2}{*}{$5.00 \mathrm{mg} / \mathrm{L}$} & Between Inbred Lines & 658.27 & 4.99 \\
\hline & Between IE sizes & 2767.16 & $21.01 *$ \\
\hline \multicolumn{4}{|c|}{ In Different Sizes of Immature Embryos } \\
\hline \multirow[t]{2}{*}{$1.00 \mathrm{~mm}$} & Between Inbred Lines & 850.39 & $13.22 *$ \\
\hline & Between 2,4-D concs. & 171.32 & 2.66 \\
\hline \multirow[t]{2}{*}{$1.50 \mathrm{~mm}$} & Between Inbred Lines & 263.75 & $47.47 *$ \\
\hline & Between 2,4-D concs. & 2295.38 & $413.17 *$ \\
\hline \multirow[t]{2}{*}{$2.00 \mathrm{~mm}$} & Between Inbred Lines & 42.13 & 2.77 \\
\hline & Between 2,4-D concs. & 695.45 & $45.79 *$ \\
\hline \multirow[t]{2}{*}{$2.50 \mathrm{~mm}$} & Between Inbred Lines & 435.38 & $13.61 *$ \\
\hline & Between 2,4-D concs. & 1241.13 & $38.79 *$ \\
\hline \multirow[t]{2}{*}{$3.00 \mathrm{~mm}$} & Between Inbred Lines & 698.36 & $68.67 *$ \\
\hline & Between 2,4-D concs. & 49.91 & 4.91 \\
\hline
\end{tabular}

*significant at $p=0.05$

and compactness of the calli, it has been identified as two types viz., Type I and Type II. Type I callus was compact and tightly packed with hard appearance which shows slow growth and will not spread much through sub-cultures. On the other hand, Type II callus was soft, nodular, loose, friable, grow quickly and more regenerative than Type I and multiplies fastly through sub-cultures (Fig. 5B and F). E. calli volumes were measured from each of 2,4-D concentrations as well as explant sizes (Fig. 4C and D). Data obtained on E. callus volume has exhibited the same trends as observed in frequency of E. callus induction, i.e., volume of E. callus obtained from different 2,4-D concentrations showed increase in volume up to $1.5 \mathrm{mg} / \mathrm{L}$ and then decreased in further concentrations; likewise, the volume of E. callus showed increasing trend up to $2 \mathrm{~mm}$ explant size and then decreased further in larger sizes of explants i.e., in 2.5 and $3.0 \mathrm{~mm}$. In NM5884, volumes of E. calli derived from any of the 2,4-D concentrations and explant sizes were more when compared with NM74C. Maximum volume of E. callus (114 cu. mm) was observed in NM5884 from $2 \mathrm{~mm}$ IE cultured on media augmented with $1.5 \mathrm{mg} / \mathrm{L}$ 2,4-D. For understanding the discrepancies showed in the data and to interpret the effect of hormonal concentrations and explant sizes among these two genotypes, the data was subjected to two-way ANOVA and represented in Table 4. In both genotypes, variation in E. callus volume was significant not only between hormonal concentrations but also in explant sizes. On the other hand, differences observed in different hormonal concentrations revealed that variation between the explant sizes was significant in all 2,4-D concentrations, whereas, between the genotypes variation was significant only in 2.5 and $4.0 \mathrm{mg} / \mathrm{L}$. When the data obtained from different explant sizes were analysed, significant variation in E. callus volume was observed neither in genotypes nor between hormonal concentrations in $1 \mathrm{~mm}$ explants. Only in 2.5 and $3.0 \mathrm{~mm}$ explants, significant variation was observed between hormonal concentrations; likewise, between genotypes, variation was significant in 1.5, 2.0 and 2.5 $\mathrm{mm}$ explants (Table 4), which indicated that in smaller explants up to $2.0 \mathrm{~mm}$ size, hormonal concentrations have 
Table 4 Analysis of variance of the effect of phytohormonal (2,4-D) concentrations, size of the immature embryos, and inbred lines on embryogenic callus volume

\begin{tabular}{|c|c|c|c|}
\hline & Source of variation & MS & $F-$ value \\
\hline \multicolumn{4}{|c|}{ In Different Inbred Lines } \\
\hline \multirow[t]{2}{*}{$\mathrm{NM} 74 \mathrm{C}$} & Between 2,4-D concentrations & 122.15 & $11.43^{*}$ \\
\hline & Between IE sizes & 1432.01 & $134.01 *$ \\
\hline \multirow[t]{2}{*}{ NM5884 } & Between 2,4-D concentrations & 461.62 & $10.71 *$ \\
\hline & Between IE sizes & 4474.08 & $103.75^{*}$ \\
\hline \multicolumn{4}{|c|}{ In Different Concentrations of 2,4-D } \\
\hline \multirow[t]{2}{*}{$0.50 \mathrm{mg} / \mathrm{L}$} & Between Inbred Lines & 325.93 & 3.74 \\
\hline & Between IE sizes & 1324.81 & $15.21^{*}$ \\
\hline \multirow[t]{2}{*}{$1.50 \mathrm{mg} / \mathrm{L}$} & Between Inbred Lines & 1133.19 & 5.26 \\
\hline & Between IE sizes & 1671.25 & $7.75^{*}$ \\
\hline \multirow[t]{2}{*}{$2.50 \mathrm{mg} / \mathrm{L}$} & Between Inbred Lines & 536.56 & $7.83^{*}$ \\
\hline & Between IE sizes & 971.84 & $14.19^{*}$ \\
\hline \multirow[t]{2}{*}{$4.00 \mathrm{mg} / \mathrm{L}$} & Between Inbred Lines & 537.12 & $10.92 *$ \\
\hline & Between IE sizes & 766.78 & $15.58^{*}$ \\
\hline \multirow[t]{2}{*}{$5.00 \mathrm{mg} / \mathrm{L}$} & Between Inbred Lines & 172.49 & 3.13 \\
\hline & Between IE sizes & 911.27 & $16.54^{*}$ \\
\hline \multicolumn{4}{|c|}{ In Different Sizes of Immature Embryos } \\
\hline \multirow[t]{2}{*}{$1.00 \mathrm{~mm}$} & Between Inbred Lines & 32.64 & 2.93 \\
\hline & Between 2,4-D concentrations & 67.29 & 6.04 \\
\hline \multirow[t]{2}{*}{$1.50 \mathrm{~mm}$} & Between Inbred Lines & 585.83 & $44.01^{*}$ \\
\hline & Between 2,4-D concentrations & 61.87 & 4.65 \\
\hline \multirow[t]{2}{*}{$2.00 \mathrm{~mm}$} & Between Inbred Lines & 3157.02 & $44.98^{*}$ \\
\hline & Between 2,4-D concentrations & 332.56 & 4.74 \\
\hline \multirow[t]{2}{*}{$2.50 \mathrm{~mm}$} & Between Inbred Lines & 366.56 & $62.01 *$ \\
\hline & Between 2,4-D concentrations & 52.84 & $8.94 *$ \\
\hline \multirow[t]{2}{*}{$3.00 \mathrm{~mm}$} & Between Inbred Lines & 35.28 & 5.17 \\
\hline & Between 2,4-D concentrations & 177.06 & $25.98^{*}$ \\
\hline
\end{tabular}

*significant at $p=0.05$

no significant effect in giving E. callus, whereas in explants measuring 2.5 and $3.0 \mathrm{~mm}$ size, 2,4-D concentration has an effect in giving E. callus rather than explants sizes.

Callus induced from all these four genotypes were identified as embryogenic and non-embryogenic calli. The non-embryogenic callus was watery, not organized and loose. This callus does not give the regeneration and become brown through age (sub-cultures). On the other hand, embryogenic callus was loose to compact, friable and cream colored which is again sub-divided into two types viz., Type I and II. Among the genotypes studied, NM81A and NM5883 resulted in non embryogenic callus (Figs. 5A and 6B), which turned to brown after few weeks (sub-cultures). Hence these two genotypes were omitted and only NM74C and NM5884 which yielded E. callus were taken into consideration for further regeneration studies.

Plantlet regeneration and hardening of plantlets

E. calli obtained from different sizes of explants maintained on different 2,4-D concentrations were harvested individually at the end of III sub-culture and transferred and maintained separately on the regeneration medium having $0.5 \mathrm{mg} / \mathrm{L}$ BAP and $0.5 \mathrm{mg} / \mathrm{L} \mathrm{Kn}$. After 15 days of growth on regeneration medium, shoot bud induction and plantlet regeneration was observed from $\mathrm{E}$. callus masses. Then these plantlets were transferred on to MS media lacking any hormones (basal medium). Shoot elongation (Fig. 6C) and rooting was induced, which were continued to maintain for two weeks in bottles (Fig. 6D). Then these plantlets were primary hardened and transferred onto soil in poly house (Fig. 6E).

The data revealed that no plantlet regeneration was observed from any of the E. calli masses derived from 1 and $3 \mathrm{~mm}$ explants at any of the 2,4-D concentrations in both the genotypes except in 1.5 and $2.5 \mathrm{mg} / \mathrm{L} \mathrm{2,4-D} \mathrm{from} 1$ $\mathrm{mm}$ explants in NM5884. All remaining three sizes of explants on all concentrations of 2,4-D, showed plantlet regeneration in both the genotypes except from 1.5 and $2.5 \mathrm{~mm}$ explants maintained at $0.5 \mathrm{mg} / \mathrm{L}$ 2,4-D in NM74C, 

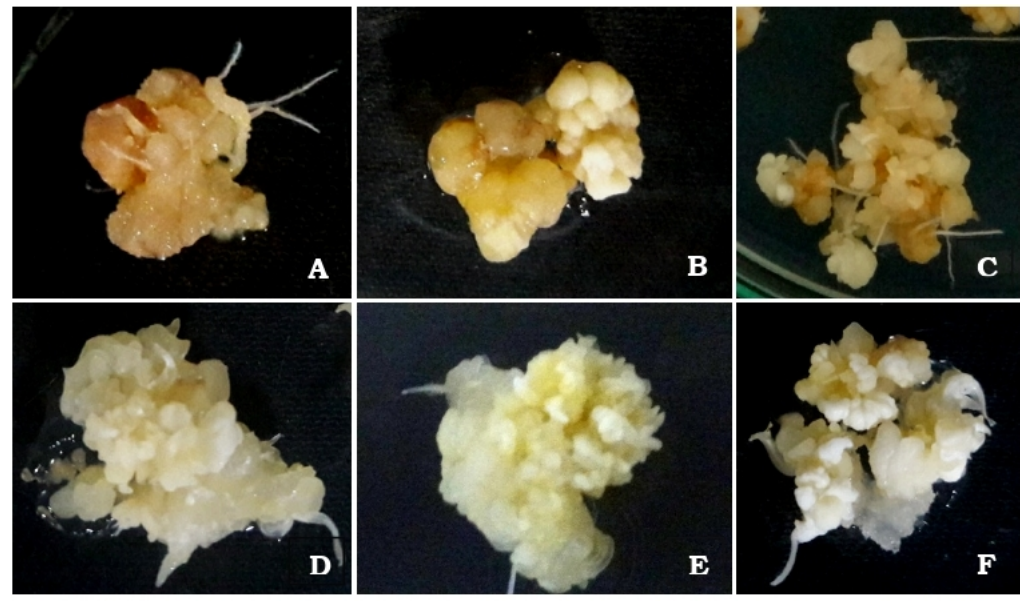

Fig. 5 Immature embryos of different maize genotypes develop two types of calli viz., non-embryogenic (A) and embryogenic calli (B-F). Embryogenic calli further differentiated into Type I, which is compact and less regenerative (B), and Type II embryogenic calli that are friable, loose, and more regenerative (C-F). Genotypes NM81A and NM5883 resulted in non-embryogenic calli (A). At some hormonal concentrations, few calli develop into an E. callus, which is a Type I callus along with a non-embryogenic callus (B); NM5884 has the most suitable genotype, which results in more Type II calli and more plantlet regeneration (C); genotype NM74C showed mixed results based on hormonal concentration and has comparatively less Type II callus

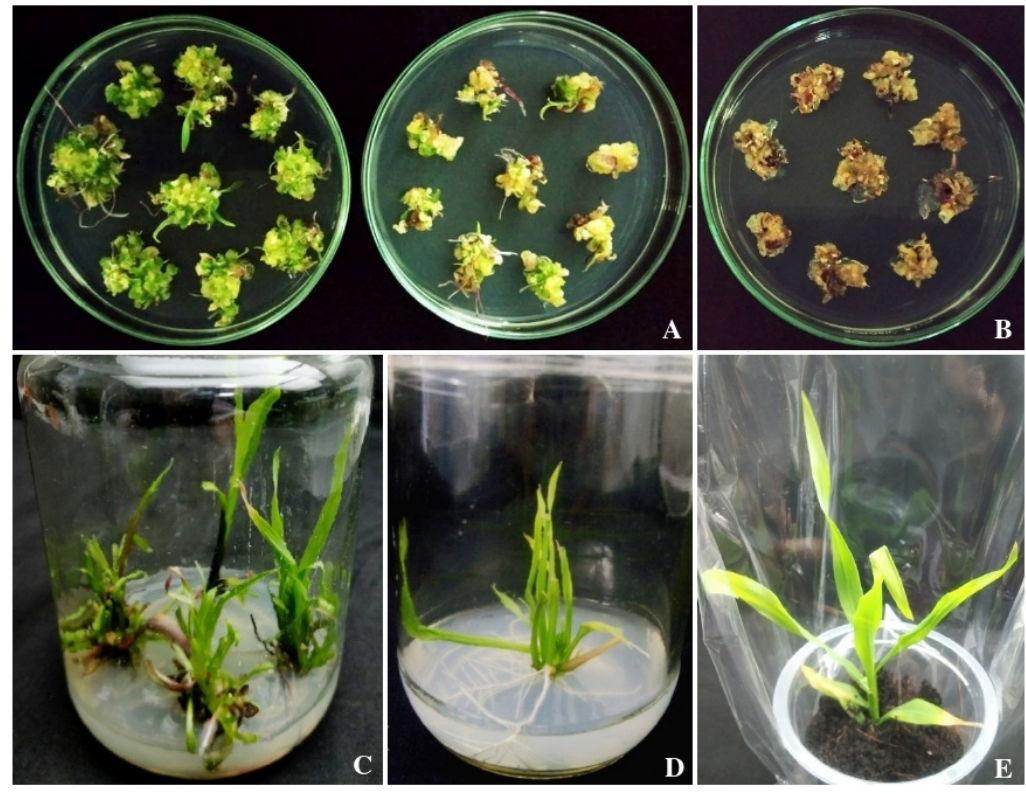

Fig. 6 Regeneration, in vitro rooting, and primary hardening of plantlets in different maize (Zea mays L.) genotypes: Maximum E. callus induction and plantlet regeneration were observed in NM5884 followed by NM74C (A); in contrast NM5883 (B) and NM81A showed scanty E. callus formation without regeneration. Plantlets sub-cultured onto MS basal medium (C) and fully grown plantlets showing root development on rooting medium (D); primary hardened rooted plantlets in plastic cups filled with sterile cocopeat (E)

where no plantlet regeneration was observed (Fig. 4E and F). In all these concentrations and sizes, number of plantlet regenerated from E. calli were higher in NM5884 than its counterpart viz., NM74C (Fig. 6A). Maximum number of plantlets were regenerated from $2 \mathrm{~mm}$ explants at $1.5 \mathrm{mg} / \mathrm{L}$ 2,4-D in both the genotypes. NM5884 resulted in highest number of plantlets of 18 , whereas, in $\mathrm{NM} 74 \mathrm{C}$ only 5 plantlets were observed (Fig. 4E and F). In almost all concentrations and sizes of explants, where the plantlet regener- ation was observed, NM5884 resulted in double the number of plantlets than the number obtained from NM74C. Among these two genotypes, NM74C resulted in more of Type I E. callus on majority of the media with different explants sizes. In contrary, NM5884 yielded more of Type II E. callus and produced more number of plantlets. Hence NM5884 was considered as best genotype for in vitro studies and to improve the germplasm through genetic transformation. 


\section{Discussion}

In vitro regeneration with very high frequency of plantlet regeneration is highly essential pre-requisite for the genetic transformation of any plant system. In monocots, establishment of regeneration protocol is more critical than dicot plants due to structural variation and composition of the tissues. Many factors like explants and its age, plant genotype, media composition viz., major and minor nutrients and vitamins, nitrogen content, hormonal concentration and their combinations etc., play a major vital role in controlling regeneration and plantlet development.

Bohorova et al. (1995) suggested that N6 medium, with lower level of nitrogen than MS, showed better callus induction and maintenance. Rooz (2002) reported high frequency of regeneration in calli derived from MS with 2,4-D in IEs. Ishida et al. (2007) and Sreenu et al. (2016a) used LS medium for maize IEs. In present study LS medium proposed by Ishida et al. 2007 supplemented with only 2,4-D has been used for callus induction and E. callus induction, later which were transferred onto media supplemented with BAP and $\mathrm{Kn}$ for plant let regeneration. Our preliminary studies revealed that the LS medium was more suitable for culturing the IEs and MS media for coleoptile nodes (Sreenu et al. 2016a; Sreenu et al. 2016b; Pavan Kumar et al. 2018) with these genotypes; hence in present study LS medium has been used. Presence of $\mathrm{AgNO}_{3}$ in medium enhances the E. callus induction by influencing the embryogenic potential of fresh callus (Giridhar et al. 2003) by acting in antagonistic way to the endogenous ethylene which damages the tissue. Both N6 and LS media used by Bohorova et al. (1995) and Ishida et al. (2007) respectively were supplemented with $\mathrm{AgNO}_{3}$.

In cereal tissue culture, influence of growth hormones is very crucial (Bhaskaran and Smith 1990) in giving the primary callus from the explants and differentiation into embryogenic callus (Rueb et al. 1994; Vikrant and Rashid 2003; Jogeswar et al. 2007). Armstrong and Green 1985, Rao et al. 1995, reported that in maize and sorghum, proline promoted the embryogenic callus production, on the other hand, Zhao et al. 2010, reported proline effect on callus induction was not significant in low concentrations. In the present study, only 2,4-D has been used for the callus induction, Zhao et al. 2010 also reported the same in sorghum that 2,4-D alone was sufficient to induce callus formation and the additional $\mathrm{Kn}$ in high concentrations $(0.6 \mathrm{mg} / \mathrm{L})$ decreased the callus induction frequency; whereas in our previous study with maize coleoptilar nodal explants, contrastingly callus induction was enhanced in presence of $\mathrm{Kn}$
(0.5 mg/L) along with 2,4-D (Pavan Kumar et al. 2018). For the regeneration, low concentration of $\mathrm{Kn}(0.5 \mathrm{mg} / \mathrm{L})$ has been used for enhancing the frequency, Zhao et al. 2010, reported, low Kn concentration $(0.2 \mathrm{mg} / \mathrm{L})$ was beneficial for keeping the calli embryogenic. High concentrations of 2,4-D results in decreased regeneration frequency (Mendoza and Kaeppler 2002). At higher concentrations of 2,4-D callus growth was drastically effected not only in giving the regeneration but also the callus became brown and watery.

Plant genotype plays an important role in giving high frequency of regenerative embryogenic callus in different cultures, including in maize (Gorji et al. 2011, Grando et al. 2013; Bohorova et al. 1995; Furini and Jewell 1994; Aguado-Santacruz et al. 2007). The maize genotypes growing in temperate areas are extensively screened and others which are growing in tropical regions are yet to be screened for their in vitro ability to give high frequencies of regenerations. Intense variation existing in maize genotypes makes it more difficult to respond in vitro for regeneration. This makes to explore and optimize the specific in vitro growth conditions for specific genotypes (Malini et al. 2015). Several reports have explained the genotypic differences in maize regarding the formation of embryogenic cultures from different explants (Frame et al. 2006; Ishida et al. 2007; Lee et al. 2007; Tomes and Smith 1985). Malini et al. 2015, focused on a standard protocol for regeneration of tropical Indian maize inbreds using IEs by adopting the protocol suggested by Bohorova et al., 1995.

Successful regeneration has been reported from different explants viz., mature embryos (Tiwari et al. 2015), nodal culture (Vladimir et al. 2006), split seeds (Al-Abed et al. 2006) and immature embryos (Duncan et al. 1985; Furini and Jewell 1994 and Bohorova et al. 1995). Among the different explants used and reported in different studies, IEs were found to be more suitable in yielding highest frequencies of callus induction and regenerative embryogenic callus. IEs also differ in giving regenerative E. callus basing on their age (days after pollination) size and season in a window of 8-20 days. Right developmental stages of IEs are obtained in a window of $8 \sim 15$ days after pollination. Obtaining right stage of immature embryo is critical and easily identified with its size which varies from $1 \sim 3$ $\mathrm{mm}$ in this window. Ishida et al. 2007 reported that this size varied among the genotypes in giving high frequencies of E. callus and regeneration. In present study, $2 \mathrm{~mm}$ IEs obtained in 8-14 days after pollination resulted in maximum regeneration. The same genotype yielded this size during $10 \sim 16$ days in rabi season. In this window of $8 \sim 14$ days, embryos attain $1.0 \sim 3.0 \mathrm{~mm}$ size which again shows variation 
in giving E. callus. Hence, both age and size of the explants have to be considered while selecting the IE explants. In tropical genotypes (in present study) the window extended up to $8 \sim 16$ days to get the approximate size for giving maximum frequencies of E. callus. In present study, explants during that age varied from 1 to $3.5 \mathrm{~mm}$, among which $2.0 \mathrm{~mm}$ size of IEs yielded maximum frequencies of calli. The size of explants varies among genotypes in that window of $8 \sim 16$ days period, in turn, within the genotype also during kharif the optimum size of $2.0 \mathrm{~mm}$ size could be obtained during $12 \sim 14$ days, whereas in rabi season it extends up to $14 \sim 16$ days. Hence explants size is crucial along with the age and genotype. Genotype NM81A which did not yield embryogenic calli in this study, resulted in good frequency of E. callus induction and regeneration with coleoptilar nodal explants (Pavan Kumar et al. 2018). Hence the genotype shows significant effect on yielding high frequencies of $\mathrm{E}$. callus induction and regeneration.

\section{Conclusion}

Effect of culture media and phytohormones on callus and E. callus induction shows much variation among different explants and different genotypes, the four genotypes studies in present study have also been used in our previous study (Pavan Kumar et al. 2018), by using coleoptilar nodal explants, where the callus induction and $\mathrm{E}$. callus induction were recorded better on MS media supplemented with 2,4-D along with $\mathrm{Kn}$. In contrary, in present study, Kn along with 2,4-D did not support in giving higher frequencies. Not only the culture media and hormones differed but also the genotypes showed contrasting results in giving regeneration, where NM5884 was found to be least responding genotype with coleoptilar nodal explant. Hence it can be concluded that the genotypes and explants play crucial role in giving high frequencies of regenerations. Next to these, media and hormones have their own effect in yielding the E. callus.

\section{Acknowledgments}

This work was financially supported by IGSTC (Indo-German Science and Technology Centre, New Delhi, India), a Binational Centre Supported by Govt. of India and Govt. of Germany. Project was sanctioned under IGSTC (2+2 scheme) (IGSTC/First Call/ICGEB-001/2011/157). The authors are thankful for the support.

\section{References}

Aguado-Santacruz GA, Garcia-Moya E, Aguilar- Acuna JL, MorenoGomez B, Preciado-Ortiz ER, Jimenez-Bremont JF, Rascon-Cruz $\mathrm{Q}$ (2007) In vitro plant regeneration from quality protein maize (QPM). In vitro Cell Dev Biol Plant 43:215-224

Ahmadabadi M, Ruf S, Bock R (2007) A leaf-based regeneration and transformation system for maize (Zea mays L.). Transgenic Research 16:437-448

Al-Abed D, Rudrabhatla S, Talla R, Goldman S (2006) Split-seed: a new tool for maize researchers. Planta 223:1355-1360

Ali F, Ahsan M, Saeed NA, Ahmed M, Ali Q, Kanwal N, Tehseen MM, Ijaz U, Bibi I, Niazi NK (2014) Establishment and optimization of callus-to-plant regeneration system using mature and immature embryos of maize (Zea mays L.). International Journal of Agriculture \& Biology 16:111-117

Armstrong CL, Green CE (1985) Establishment and maintenance of friable, embryogenic maize callus and the involvement of L-Proline. Planta 164:207-214

Barloy D, Beckert M (1993) Improvement of regeneration ability of androgenetic embryos by early anther transfer in maize. Plant Cell, Tissue and Organ Culture 33:45-50

Bhaskaran S, Smith RH (1990) Regeneration in cereal tissue culture: a review. Crop Science 30:1328-1337

Bohorova NE, Van GM, Rajaram S, Hoisington DA (1995) Tissue culture response of CIMMYT elite bread wheat cultivars and evaluation of regenerated plants. Cereal Research Communications 23:243-249

Conger BV, Novak FJ, Afza R, Erdelsky K (1987) Somatic embryogenesis from cultured leaf segments of Zea mays $\mathrm{L}$. Plant Cell Reports 6:345-347

Duncan DR, Williams ME, Zehr BE, Widholm JM (1985) The production of callus capable of plant regeneration from immature embryos of numerous Zea mays L genotypes. Planta 165:322-332

Frame BR, McMurray JM, Fonger TM, Main ML, Taylor KW, Torney FJ, Paz MM, Wang K (2006) Improved Agrobacteriummediated transformation of three maize inbred lines using MS salts. Plant Cell Reports 25:1024-1034

Furini A, Jewell DC (1994) Somatic embryogenesis and plant regeneration from immature embryos of tropical and subtropical Zea mays L genotypes. Maydica 39:155-164

Giridhar P, Indu EP, Vijaya Ramu D, Ravishakar GA (2003) Effect of silver nitrate on in vitro shoot growth of Coffee. Tropical Science 43:44-146

Gorji AH, Zolnoori M, Jamasbi A, Zolnoori Z (2011) In vitro plant generation of tropical maize genotypes. International Conference on Environmental Biomedical and Biotechnology IPCBEE 16:52-59

Grando MF, Varnier ML, Silva MRD, Emydio BM, Pereira LR, Suzin M (2013) Immature tassels as alternative explants in somatic embryogenesis and plant regeneration in south Brazilian maize genotypes. Acta Scientiarum Agronomy 35:39-47

Green CE, Phillips RL (1975) Plant regeneration from tissue cultures of maize. Crop Science 15:417-421 
Ishida Y, Hiei Y, Komari T (2007) Agrobacterium-mediated transformation of maize. Nature Protocols 2:1614-1621

Ismaili A, Mohammadi PP (2016) Effect of genotype induction medium carbohydrate source and polyethylene glycol on embryogenesis in maize (Zea mays L.) anther culture. Acta Physiologiae Plantarum 38:74

Jogeswar G, Ranadheer D, Anjaiah V, Kishor PBK (2007) High frequency somatic embryogenesis and regeneration in different genotypes of Sorghum bicolor (L) Moench from immature inflorescence explants. In Vitro Cell Dev Biol Plant 43: 159-166

Lee BL, Kennon AR, Chen X, Jung TW, Ahn BO, Lee JY, Zhang ZJ (2007) Recovery of transgenic events from two highly recalcitrant maize (Zea mays L) genotypes using Agrobacteriummediated standar- binary- vector transformation. Maydica 52:457-469

Linsmaier E, Skoog F (1965) Organic growth factor requirements of tobacco tissue culture. Physiol Plant 18:100-127

Malini N, Anandakumar CR, Hari Ramakrishnan S (2015) Regeneration of Indian maize genotypes (Zea mays L.) from immature embryo culture through callus induction. J Appl Nat Sci 7:131-137

Mendoza MG, Kaeppler HF (2002) Auxin and sugar effects on callus induction and plant regeneration frequencies from mature embryos of wheat (Triticum aestivum $\mathrm{L}$ ). In Vitro Cell Dev Biol Plant 38:39-45

Morocz C, Donn G, Nemeth J, Dudits D (1990) An improved system to obtain fertile regenerates via maize protoplast isolated from highly embryogenic suspension culture. Theoretical and Applied Genetics 80:721-726

Murashige T, Skoog F (1962) A revised medium for rapid growth and bio assays with tobacco tissue cultures. Physiologia Plantarum 15:473-497

Mushke R, Yarra R, Bulle M (2016) Efficient in vitro direct shoot organogenesis from seedling derived split node explants of maize (Zea mays L.). Journal of Genetic Engineering and Biotechnology 14:49-53

O'Connor-Sanchez A, Cabrera-Ponce JL, Valdez-Melara M, Téllez-Rodríguez P, Pons-Hernández JL, Herrera-Estrella L (2002) Transgenic maize plants of tropical and subtropical genotypes obtained from calluses containing organogenic and embryogenic-like structures derived from shoot tips . Plant Cell Reports 21:302-312

Pareddy DR, Petolino JF (1990) Somatic embryogenesis and plant regeneration from immature inflorescences of several elite inbreds of maize. Plant Science 67:211-219

Pavan Kumar G, Sreenu P, Sridevi M, Reddy MK, Sateesh Kumar P (2018) Coleoptilar node - A season-independent explant source for in vitro culture in maize (Zea mays L.). Journal of
Applied Biology and Biotechnology 6:20-28

Rao AM, Sree KP, Kishor PBK (1995) Enhanced plant regeneration in grain and sweet sorghum by asparagine proline and cefotaxime. Plant Cell Rep15:72-75

Ray DS, Ghosh PD (1990) Somatic embryogenesis and plant regeneration from cultured leaf explants of Zea mays L. Annals of Botany 66:497-500

Rooz BBK (2002) Plastid transformation in maize: construction and testing of vector. Dissertation, Post Graduate School, Indian Agricultural Research Institute, New Delhi, India

Rueb S, Leneman M, Schilperoort RA, Hensgens LAM (1994) Efficient plant regeneration through somatic embryogenesis from callus induced on mature rice embryos (Oryza sativa L). Plant Cell Tissue Organ Cult 36:259-264

Sairam RV, Parani M, Franklin G, Lifeng Z, Smith B, MacDougall J, Wilber C (2003) Shoot meristem: an ideal explant for Zea mays L. transformation. Genome 46:323-329

Snedecor GW, Cochran WG (1968) Statistical Methods. The Iowa State University Press. Ames, Iowa, USA Oxford and IBH publishing Co Pvt Ltd New Delhi

Sreenu P, Sridevi M, Kumar PS, Reddy MK, Sailaja D, Kumar GP (2016a) Optimization of Some Influential Factors In Maize Genetic Transformation Through Microprojectile Bombardment. Int J Recent Sci Res 7:10517-10522

Sreenu P, Kumar PS, Reddy MK, Sailaja D, Kumar GP (2016b) Resourceful and high efficiency Agrobacterium mediated transformation of maize (Zea mays L.) using coleoptilar nodal explants. Int J Curr Res Biosci Plant Biol 3:1-9

Tiwari S, Agrawal PK, Pande V, Gupta HS (2015) Callus induction and whole plant regeneration in sub-tropical maize (Zea mays L.) using mature embryos as explants. Indian Journal of Genetics and Plant Breeding 75:330-335

Tomes DT, Smith OS (1985) The effect of parental genotype on initiation of embryogenic callus from elite maize (Zea mays L) germplasm. Theoretical and Applied Genetics 70:505-509

Vikrant, Rashid A (2003) Somatic embryogenesis or shoot formation following high 24-D pulse-treatment of mature embryos of Paspalum scrobiculatum. Biol Plant 46:297-300

Vladimir S, Gilbertson L, Adae P, Duncan D (2006) Agrobacterium mediated transformation of seedling-derived maize callus. Plant Cell Rep 25:320-328

Zhao L, Liu S, Song S (2010) Optimization of callus induction and plant regeneration from germinating seeds of sweet sorghum (Sorghum bicolor Moench). Afr J Biotechnol 9:2367-74

Zhong H, Srinivasan C, Sticklen MB (1992) In-vitro morphogenesis of corn (Zea mays L.): II Differentiation of multiple shoot clumps and somatic embryos from shoot tips. Planta 187: 483-489 